\title{
RSV infection in a macrophage-cell line activates the non-canonical NF-kB pathway and induces pro-inflammatory cytokine expression
}

\author{
O. DEL MORAL-HERNÁNDEZ ${ }^{1,2}$, C. SANTIAGO-OLIVARES ${ }^{1}$, E. RIVERA-TOLEDO ${ }^{1}$, J. GAONA ${ }^{3}$, \\ E. CASTILLO-VILLANUEVA ${ }^{1}$, B. GÓMEZ ${ }^{1 *}$
}

\begin{abstract}
${ }^{1}$ Laboratorio de Virología, Departamento de Microbiología y Parasitología, Facultad de Medicina de la Universidad Nacional Autónoma de México, Ciudad Universitaria, Ciudad de México C. P. 04510, México; ${ }^{2}$ Laboratorio de Virología, Facultad de Ciencias Químico Biológicas de la Universidad Autónoma de Guerrero, Avenida Lázaro Cárdenas S/N, Ciudad Universitaria, C. P. 39090, Chilpancingo, Guerrero, México; ${ }^{3}$ Unidad de Biotecnología Médica y Farmacéutica, Centro de Investigación y Asistencia en Tecnología y Diseño del Estado de Jalisco A.C., Avenida Normalistas 800, Colinas de la normal, Guadalajara, Jalisco, C. P. 44270, México
\end{abstract}

Received April 25, 2017; revised September 13, 2017; accepted March 26, 2018

\begin{abstract}
Summary. - Respiratory syncytial virus (RSV) is a highly prevalent infectious agent that causes severe respiratory tract illnesses in infants and children worldwide. Children who have suffered severe RSV infections during infancy are prone to develop recurrent episodes of wheezing and asthma that may be associated with viral persistence. RSV infections in humans and animal models are characterized by extensive inflammatory responses. Epithelial cell lines acutely infected by RSV have shown activation of the NF- $\mathrm{BB}$ signaling through two independent pathways: the canonical pathway, mediated by RelA and p50 subunits, and the non-canonical pathway, mediated by the subunits RelB and p52. Herein, we investigated the state of activation of the canonical and non-canonical NF-kB signaling pathways in macrophages either acutely or persistently infected by RSV and examined the expression of pro-inflammatory mediators. Activation of NF- $\mathrm{kB}$ subunits was analyzed through Western blot assays using acutely RSV-infected epithelial cells as a control. The expression levels of two proinflammatory cytokines and a chemokine were determined by quantitative RT-PCR and through immunobead assays. The results showed that p52 was abundant during acute and persistent RSV infection, indicating that macrophages predominantly activate the non-canonical pathway. We also observed activation of IL- $1 \beta$, TNF- $\alpha$ and CCL5/RANTES transcription, though at higher levels in persistently infected macrophages than in acutely infected macrophages. However, the protein levels of these cytokines/chemokine did not correlate with their mRNA transcription, as quantitation displayed higher levels during acute infection than in persistent infection, suggesting post-transcriptional regulation by RSV persistence.
\end{abstract}

Keywords: RSV-persistence; NF- $\kappa$ B canonical pathway; NF- $\kappa B$ non-canonical pathway; macrophages; proinflammatory cytokines

\section{Introduction}

Respiratory syncytial virus (RSV), a non-segmented negative-stranded RNA virus, is a major cause of serious lower respiratory tract infections in infants and young chil-

*Corresponding author: E-mail: begomez@unam.mx; phone: +5255-5623-2469.

Abbreviations: IRF-3 = interferon regulatory factor 3; pi = postinfection; RSV = respiratory syncytial virus dren worldwide (Hall et al., 2013). It also causes a considerable disease burden in elderly and immunocompromised populations (Branche and Falsey, 2015). Young children who have recovered from severe RSV bronchiolitis often develop chronic and recurrent respiratory problems such as wheezing and asthma (Szabo et al., 2013). The link between severe RSV disease and the development of respiratory sequelae has been clearly established in several well-controlled prospective epidemiological studies (Openshaw et al., 2003) that have suggested that RSV persists for a long time in individuals 
with these conditions (Sikkel et al., 2008), possibly causing chronic inflammation. Additionally, RSV subtype A has been found in patients with chronic obstructive pulmonary disease, both in the stable phase and during severe exacerbation, suggesting an association between persistent RSV infection and this disease (Kokturk et al., 2015). Furthermore, evidence in mouse models and humans supports the hypothesis that RSV can persist in a latent state or at a low level of viral replication in the lungs, contributing to long-term airway disease (Mejías et al., 2008; Piedimonte, 2013).

Studies in vitro and in vivo have demonstrated that RSV is among the most potent biological stimuli for inducing chemokine and cytokine production, a process that is largely controlled by activation of transcription factors as NF- $\mathrm{kB}$ and interferon regulatory factor 3 (IRF-3) during viral infection (Génin et al., 2000). NF-kB is a family of inducible transcription factors involved in diverse biological processes (i.e., immune response, cell survival, cell differentiation) whose activation is tightly regulated through sequestration in the cytoplasm by specific inhibitors of NF- $\mathrm{KB}$ (IKBs), preventing their nuclear translocation in resting cells. Inducible processing of precursor proteins also regulates activation of some members of the NF- $\mathrm{B}$ f family (Shih et al., 2011; Sun, 2012).

Five NF- $\kappa B$ proteins, divided into two groups, have been identified in mammals. The first group includes the RelA, RelB and c-Rel proteins, which are synthesized as mature products that do not require proteolytic processing, while the second group contains the large precursor molecules p105 and p100, encoded by the Nfkb1 and Nfkb2 genes, respectively, which require proteasome-mediated degradation to produce their respective mature forms, p50 and p52 (Karin and Lin, 2002). The transcriptional activity of NF- $\mathrm{kB}$ depends on the formation of heterodimers or homodimers between the five components and signaling can occur through the canonical and non-canonical pathways; each pathway requires specific and distinct signaling molecules (Gilmore, 2006; Siebenlist et al., 1994).

The canonical pathway is activated by a diverse range of immune receptors upon ligand binding, leading to nuclear translocation of RelA/p50 and c-Rel/p50 heterodimers which play key roles in host defense and inflammatory responses (Karin and Lin, 2002). This pathway is characterized by constitutive processing of p105 into p50, although specific stimuli enhance its degradation and transcriptional activity (Hayden and Ghosh, 2008). In contrast, the non-canonical NF- $\kappa B$ pathway relies on inducible processing of the precursor protein $\mathrm{p} 100$ and predominantly activates the transcriptional activity of the RelB/p52 heterodimer to target genes responsible for secondary lymphoid organ development, T-cell differentiation, as well as B-cell and dendritic cell maturation (Sun, 2012).

Acute RSV infection in human lung epithelial cells (A549) induces an early ( $6 \mathrm{~h}$ post-infection (pi)) nuclear accumulation of RelB and p52 (Choudhary et al., 2005), while RelA DNAbinding peaks $24 \mathrm{~h}$ pi, indicating that acute RSV infection activates the non-canonical pathway earlier than the canonical pathway in epithelial cells (Jamaluddin et al., 1998).

RSV acute infection in epithelial cells triggers host innate immune responses through activation of the transcription factors NF-kB (Dave et al., 2014; Garofalo et al., 1996) and IRF-3 (Grandvaux et al., 2014; Liu et al., 2007), which coordinately regulate the expression of pro-inflammatory cytokines. However, while macrophages are susceptible to RSV infection in vivo and in vitro, no information about the activation of NF- $\kappa B$ pathways in these cells acutely or persistently infected by RSV has been documented (Panuska et al., 1992; Ravi et al., 2013). Our group has developed an in vitro model of RSV persistence in macrophages and we recently reported that IRF-3 is constitutively activated, inducing IFN- $\beta$ synthesis and release (Rivera-Toledo et al., 2015).

Herein, we investigated in the same in vitro model whether acute and persistent RSV infection activates both canonical and non-canonical NF- $\mathrm{kB}$ pathways and examined the expression of pro-inflammatory cytokines.

\section{Materials and Methods}

Virus and cell lines. The wild type RSV strain Long (wtRSV) has been the prototype virus used in our laboratory. The virus's origin and procedures for propagation, purification and evaluation of its infectivity in Vero cells have been previously reported (Sarmiento et al., 2002). The murine macrophage-like cell line P388D1 was originally obtained from the ATCC (TIB-63). Our laboratory had previously obtained a sub-line of $\mathrm{P} 388 \mathrm{D} 1$ persistently infected with wtRSV, named MФP (Sarmiento et al., 2002). The original P388D1 cell line has been sub-cultured in parallel with МФP and used as control, mock-infected cells $(\mathrm{M} \Phi \mathrm{N})$. Both cell lines were maintained by sub-culturing. МФP passages from 72 to 87 were used in this study. Throughout the passages, the persistence of viral genome was monitored by detecting the mRNA of the gene N by conventional RT-PCR (Gaona et al., 2014). Extracellular viral infectivity titer was $1-2 \times 10^{2} \mathrm{TCID}_{50} / \mathrm{ml}$ and no syncytia were observed (Sarmiento et al., 2002). Cell cultures were propagated in RPMI 1640 medium (GIBCO/BRL) supplemented with 5\% heatinactivated fetal bovine serum (FBS) (Biowest, México).

Western blot. Total protein extracts were prepared with the ProteoJET ${ }^{\mathrm{TM}}$ mammalian cell lysis reagent kit (Fermentas, USA), from $1 \times 10^{6} \mathrm{M} \Phi \mathrm{N}, \mathrm{M} \Phi \mathrm{P}$ or macrophages infected with RSV for the indicated time (acute infection, MФA). Total proteins were also extracted from A549 epithelial cells infected for the indicated time as a control (acute infection, A549A). Then, $50 \mu \mathrm{g}$ of proteins were mixed with Laemmli sample buffer, boiled, separated by $12 \%$ SDS-PAGE, and transferred onto PVDF membranes (Amersham, USA) as previously described (Gaona et al., 2014). The commercial antibodies used were anti-NF- $\kappa B$ p65 and anti-NF- $\kappa$ B p100/p52 (Cell Signaling Technol- 
ogy, USA); anti-RelB, anti-c-Rel, anti-NF- $\kappa$ B p50 and anti- $\beta$ tubulin (Santa Cruz Biotechnology, USA). The secondary antibodies were anti-rabbit-HRP (Zymed, USA) or anti-goat-HRP (Zymed). Membranes were stripped and reprobed using anti-GAPDH antibodies (Zymed). Finally, immunoreactive bands were visualized using the ECL chemiluminescence system (Amersham).

Quantitative RT-PCR. Total RNA was extracted from MФN, MФA and MФР $\left(2 \times 10^{6}\right.$ cells) with Trizol (Invitrogen), following the manufacturer's instructions. Then, RNA $(2 \mu \mathrm{g})$ was reverse transcribed with RNA transcriptase Superscript II (Invitrogen, USA). TaqMan real-time PCR was performed with primers and probes (Assay on demand $20 \times$ mix) for IL- $1 \beta$, TNF- $\alpha$ and CCL-5/RANTES genes and GAPDH as control, using TaqMan assay reagent master mix (Applied Biosystems, USA). Cycling parameters were established according to the manufacturer's protocol. Triplicate CT values were analyzed in Microsoft Excel, using the comparative $\mathrm{CT}(\Delta \mathrm{T})$ method as described by the manufacturer (Applied Biosystems). The amount of mRNA from each target gene $(2-\triangle \Delta \mathrm{CT})$ was obtained by normalizing it to the endogenous reference (GAPDH) sample.

Immunobead assay. $\mathrm{M} \Phi \mathrm{N}$ and $\mathrm{M} \Phi \mathrm{P}\left(5 \times 10^{5}\right.$ cells $)$ were seeded in 12 well plates. Cells were allowed to adhere overnight before $\mathrm{M} \Phi \mathrm{N}$ were mock- or RSV-infected for $2 \mathrm{~h}$ at multiplicity of infection (m.o.i.) of 3, and then extensively rinsed with PBS to eliminate viral inoculum. After that, RPMI 1640 medium supplemented with $2 \%$ FBS (500 $\mu$ l) was added and conditioned media were collected before $\left(\mathrm{t}_{0}\right)$ and after $16 \mathrm{~h}$ of incubation $\left(\mathrm{t}_{16}\right)$, centrifuged $(352 \times \mathrm{g})$ for $10 \mathrm{~min}$ and stored at $-20^{\circ} \mathrm{C}$ until analyzed. Milliplex MAP mouse cytokine/chemokine Magnetic bead panel immunoassay (MCYTOMAG-70K, Millipore Corpora- tion, USA) was used to quantify expression of cytokines/chemokine in conditioned media (IL-1 $\beta$, TNF- $\alpha$ and CCL5/RANTES), according to manufacturer's instructions. Concentrations ( $\mathrm{pg} / \mathrm{ml}$ ) were determined in duplicates for each sample, for three independent samples, by using an automated immunoassay analyzer (MAGPIX, Millipore).

\section{Results}

$N F-\kappa B-p 100$ precursor is overexpressed in persistently $R S V$-infected macrophages

Initially, we analyzed the basal expression of the five NF- $\kappa B$ subunits in persistently RSV-infected macrophages (MФP) compared to mock-infected macrophages (MФN). Western blots showed that all five subunits were expressed at similar levels in both types of cell cultures (Fig. 1a) except for p100, which was significantly increased in MФP (3-fold, Fig. 1b). This suggests that persistent RSV infection in macrophages induces selective overexpression of the $\mathrm{p} 100$ precursor, representative of the non-canonical NF- $\kappa$ B pathway.

Kinetics of NF- $\kappa B$ subunit expression and processing during acute- $R S V$ infection

To determine whether the expression pattern of NF- $\kappa B$ subunits is similar between acute and persistent RSV infection, we next performed a kinetic assay to evaluate the expression (a)

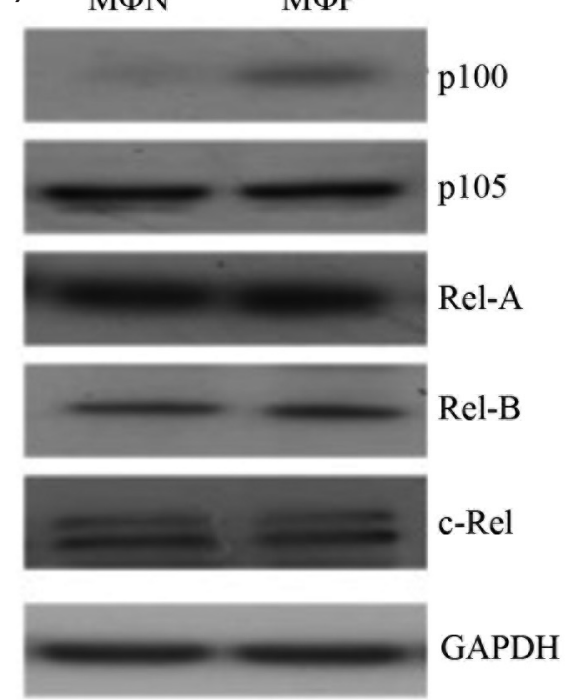

(b)

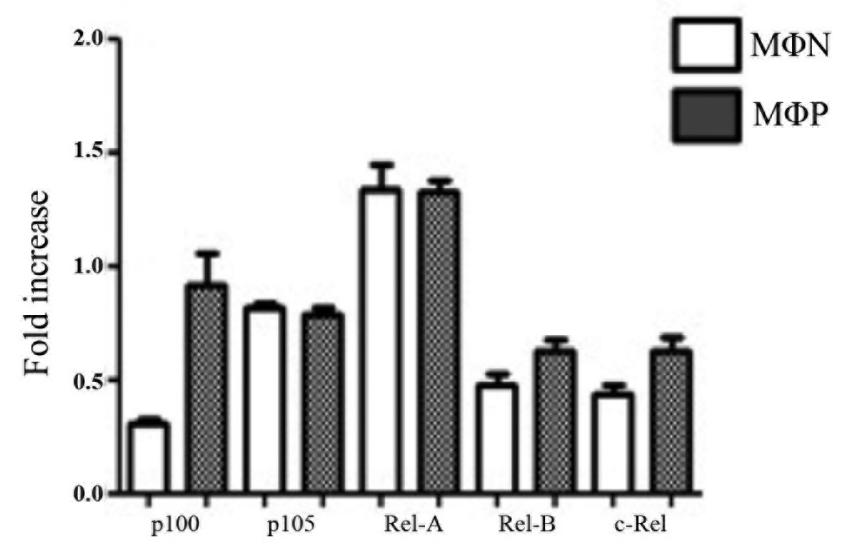

Fig. 1

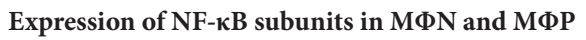

(a) Comparative analysis of protein expression by Western blot of the five NF- $\mathrm{kB}$ subunits in MФN and in MФP. The expression level of GAPDH, a housekeeping protein, was used as a loading control. (b) Semi-quantitative analysis of three independent experiments to evaluate expression of the five NF- $\mathrm{kB}$ subunits, performed by using the software QuantityOne. 
(a)
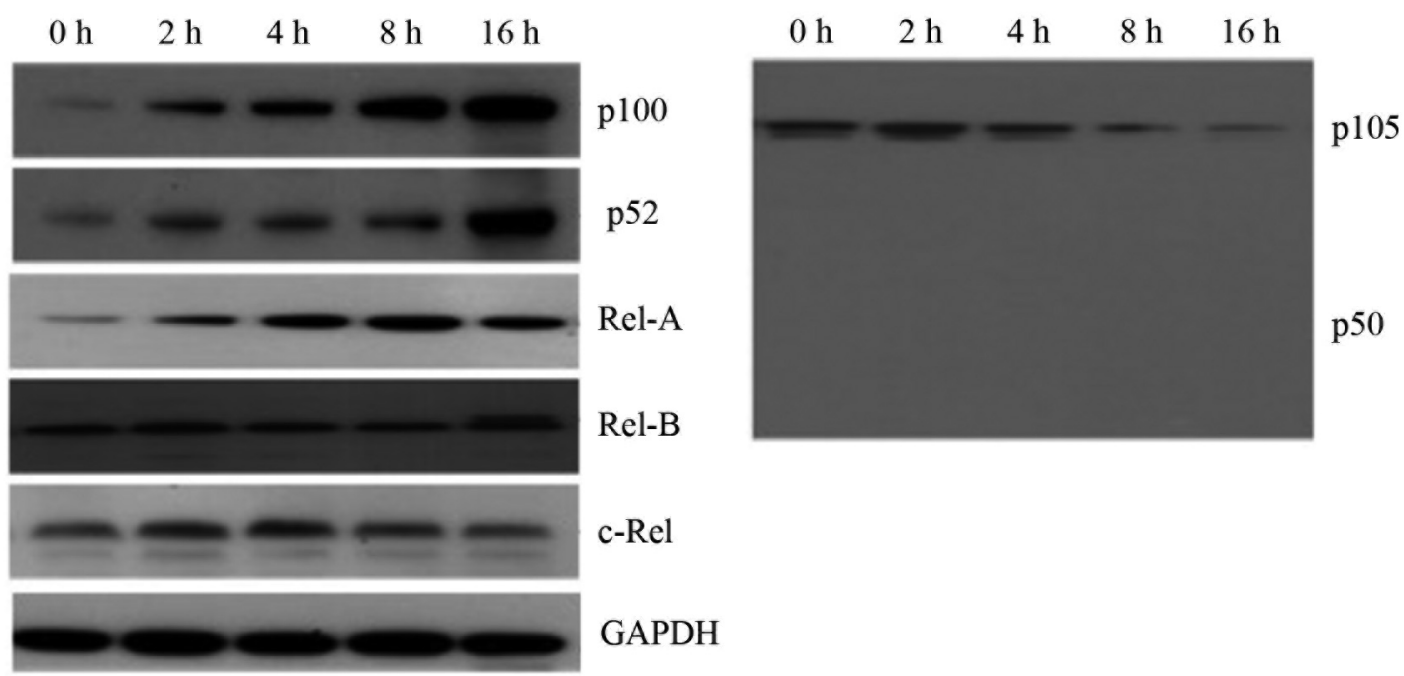

p52

(b) p100

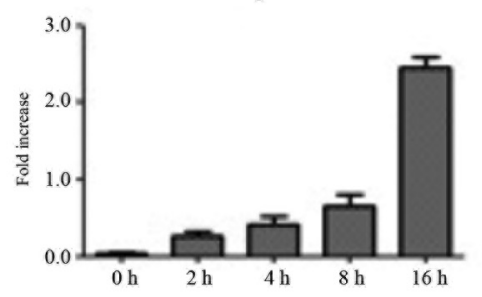

Rel-A
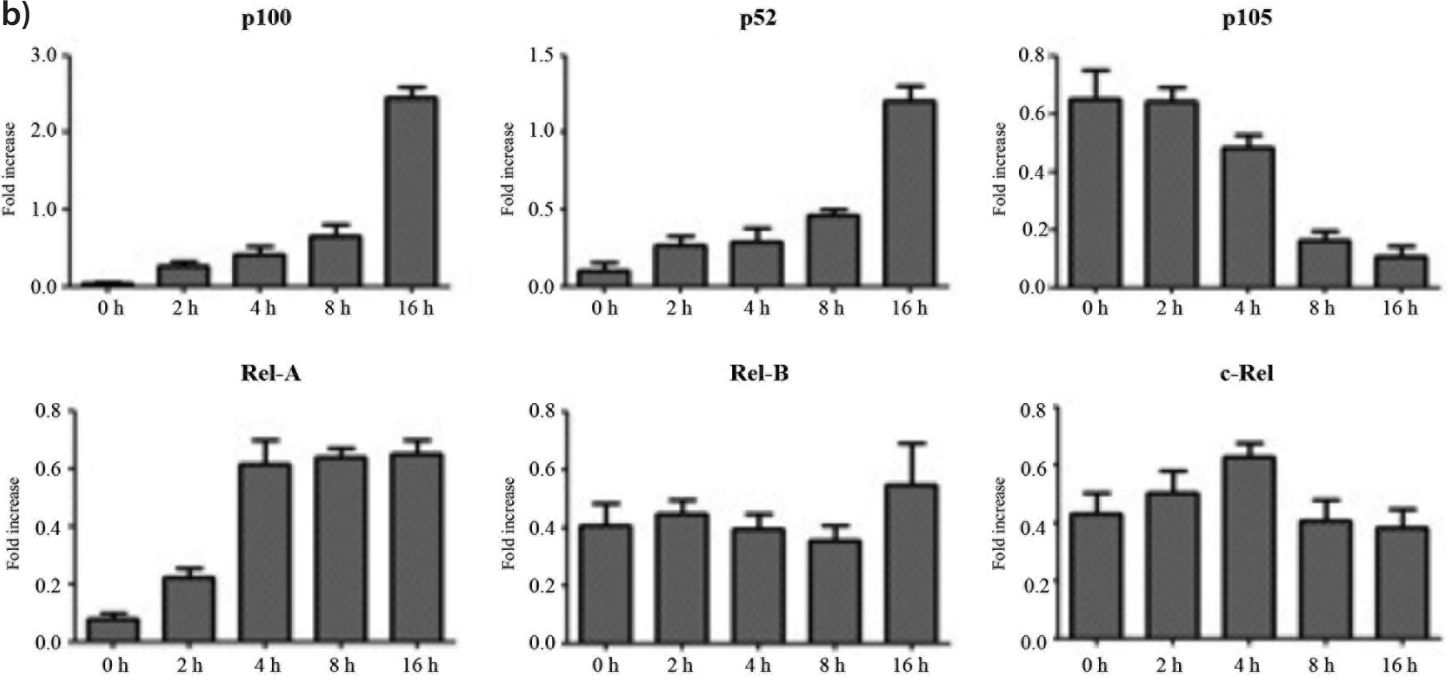

c-Rel

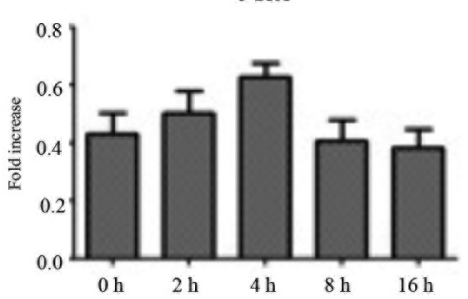

Fig. 2

Kinetics of NF-kB subunit expression

(a) Kinetics of NF- $\kappa \mathrm{B}$ subunit activation in macrophages acutely infected with RSV at m.o.i. of 3 . Total proteins at different times post-infection were assayed by Western blot. P105 and p100 subunits and their active forms, p50 and p52, were analyzed. GAPDH was used as a loading control. (b) Densitometry determinations of NF- $\mathrm{kB}$ subunit protein levels by Western blot at different times post-infection.

of NF- $\mathrm{kB}$ precursors and processed forms during a de novo RSV infection. The results showed that acute infection in macrophages (MФA) led to a time-dependent increase in the expression of RelA and p100. Additionally, processing of p100 into p52 increased over time (Fig. 2a). The maximum level of expression was reached earlier for RelA (at $4 \mathrm{~h}$ pi) than for p100 and p52 (at $16 \mathrm{~h} \mathrm{pi).} \mathrm{Densitometry} \mathrm{analysis} \mathrm{displayed}$ fold-increase values at peak levels of 6.1,49.6 and 7.3 for RelA, p100 and p52, respectively (Fig. 2b). In contrast, while p105 was expressed at high levels at the beginning of the infection
( $0 \mathrm{~h} \mathrm{pi}$ ), at $4 \mathrm{~h}$ pi we observed a significant reduction of this precursor and its levels continued to decline up to 6 -fold by 16 $\mathrm{h}$ pi. Interestingly, despite the drastic decrease of the precursor p105, we did not detect the mature p50 protein.

\section{Processing of $N F-\kappa B$ subunits during persistent $R S V$ infection}

Subsequently, we examined whether persistent RSV in МФP induced processing of the precursors p105 and p100. 
(a)

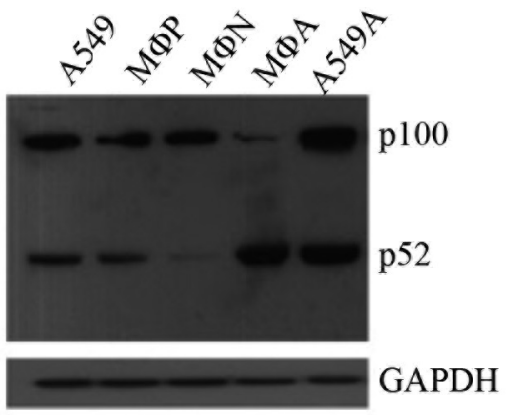

(b)

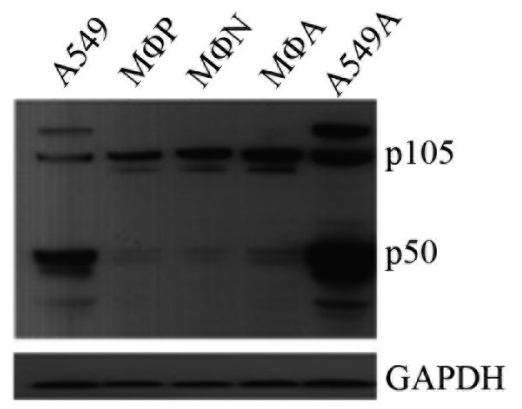

(c)

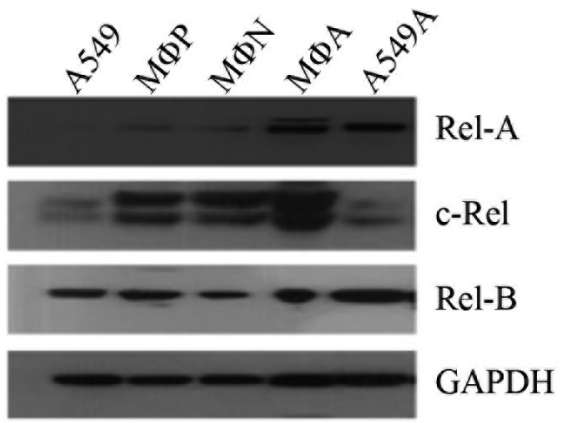

Fig. 3

Expression levels of NF-kB subunits in macrophages differs from those in epithelial cells

(a) Expression of NF- $\kappa B$ subunits of the non-canonical pathway in mock-infected A549 epithelial cells, in MФP, in MФN, in MФA and in acutely infected A549 cells (A549A). (b) Expression of NF- $\mathrm{BB}$ subunits of the canonical pathway in same types of cells as in panel (a). (c) Expression levels of RelA, c-Rel and RelB in same types of cells as panel (a). The loading control GAPDH is shown.

As a positive control of NF- $\kappa \mathrm{B}$ precursor processing, we used A549 cells acutely infected for $16 \mathrm{~h}$ with RSV (A549A). We observed partial but constitutive processing of p100 into p52 in МФР (Fig. 3a), with precursor and mature protein detected at similar levels. In contrast, $\mathrm{M} \Phi \mathrm{N}$ showed very low levels of p52, but upon RSV acute infection almost all p100 was proteolyzed, leading to a dramatic increase in $\mathrm{p} 52$. The precursor p105 was observed in MФP, MФN and MФA; nevertheless, no accumulation of p50 was detected even after acute RSV infection (Fig. 3b). RelA was increased only by acute infection but not by persistent infection; c-Rel and RelB did not show significant expression changes. In contrast, A549 cells showed constitutive processing of p100 and p105, which was prominently enhanced by RSV acute infection (Fig. 3a,b,c), and increased levels of RelA were also observed (Fig. 3c). These results indicated that RSV activated both the canonical and non-canonical pathways in epithelial cells at $16 \mathrm{~h} \mathrm{pi}$, while acute and persistent RSV infection in macrophages preferentially induced the non-canonical pathway.

Pro-inflammatory cytokine/chemokine expression during acute and persistent RSV infection

Finally, to determine whether there exists an association between the preferential activation of the non-canonical
NF- $\kappa$ B pathway and expression of pro-inflammatory mediators during RSV infection, we determined mRNA levels of the cytokines IL- $1 \beta$ and TNF- $\alpha$, as well as the chemokine CCL5/RANTES in MФP and MФA, compared to the MФN control. Quantitative RT-PCR showed that expression of the three evaluated genes were elevated in both $М Ф P$ and МФA, although viral persistence induced the highest gene expression levels when compared to acute infection (Fig. 4). Unexpectedly, when the cytokines/chemokine protein levels from conditioned media were evaluated, the quantities of IL- $1 \beta$, TNF- $\alpha$, and CCL5/RANTES were consistently higher in MФA than in MФP, suggesting that during RSV persistence, transcription of these pro-inflammatory genes is high but regulated at the post-transcriptional level, in contrast with acute RSV infection.

\section{Discussion}

During evolution, viruses have acquired the ability to hijack or modulate cellular transcription factors to control host metabolism and antiviral responses to their own advantage (Santoro et al., 2003). Activation of the NF- $\kappa B$ signaling pathway is an early response upon pathogen invasion, playing a critical role in inducing inflammation and cell survival 
(a)
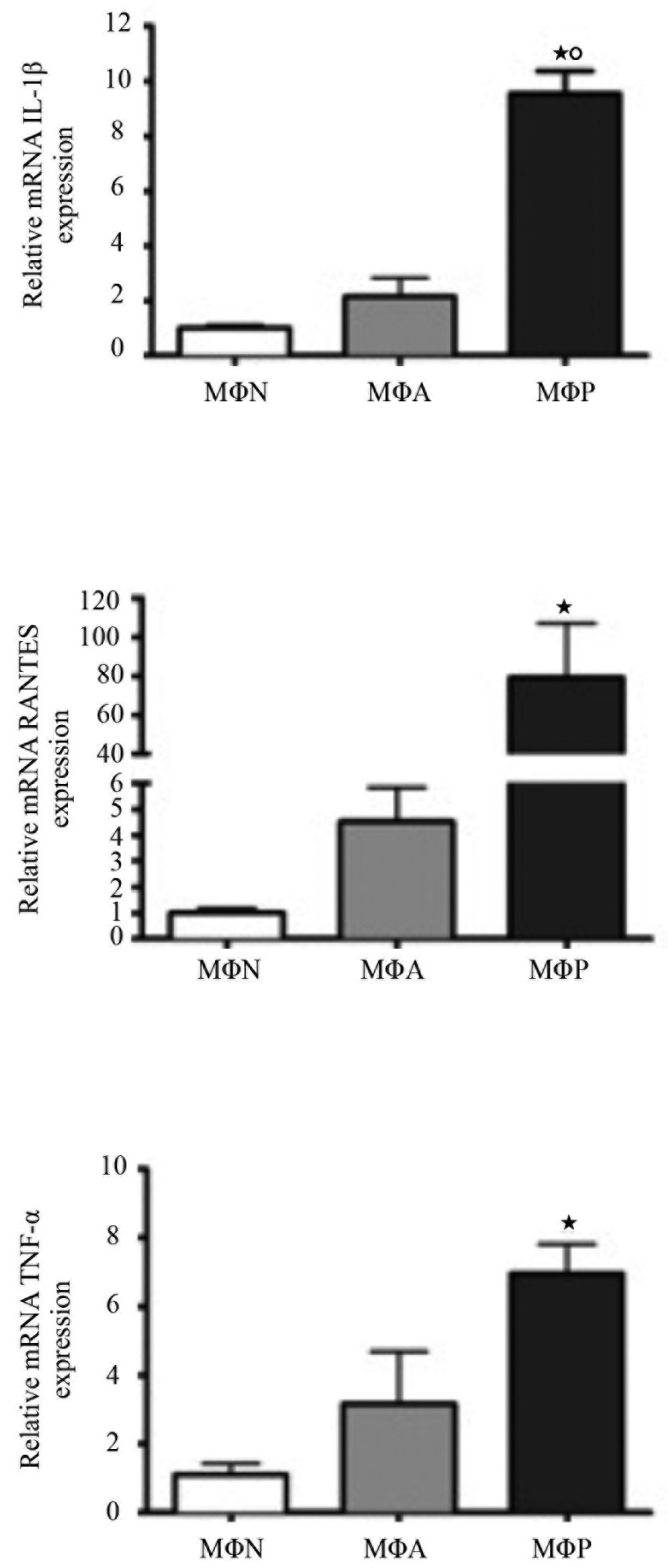

(b)

\section{IL-1及}

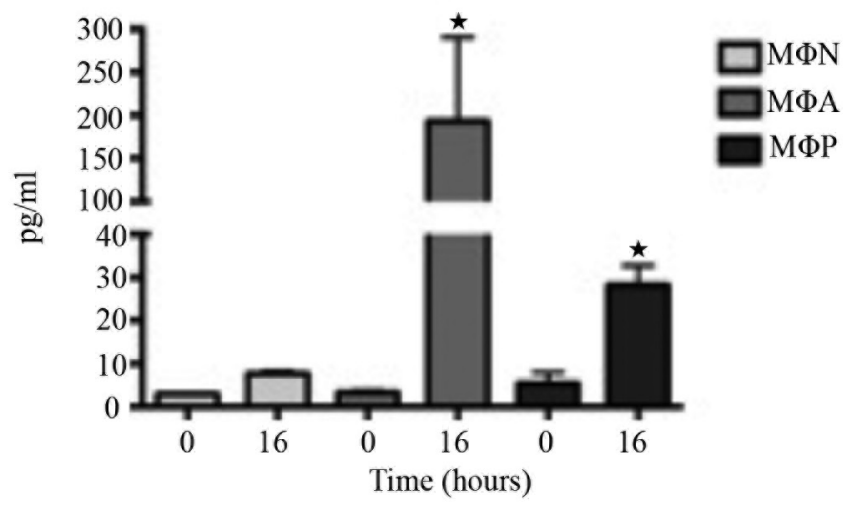

RANTES

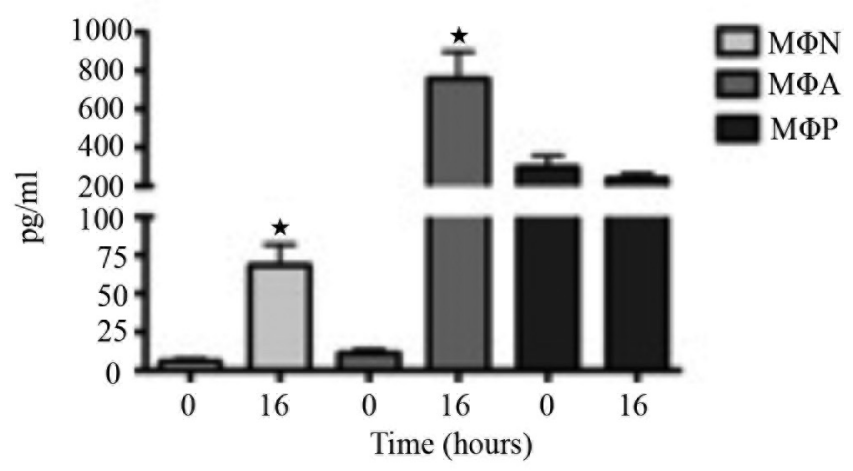

TNF- $\alpha$

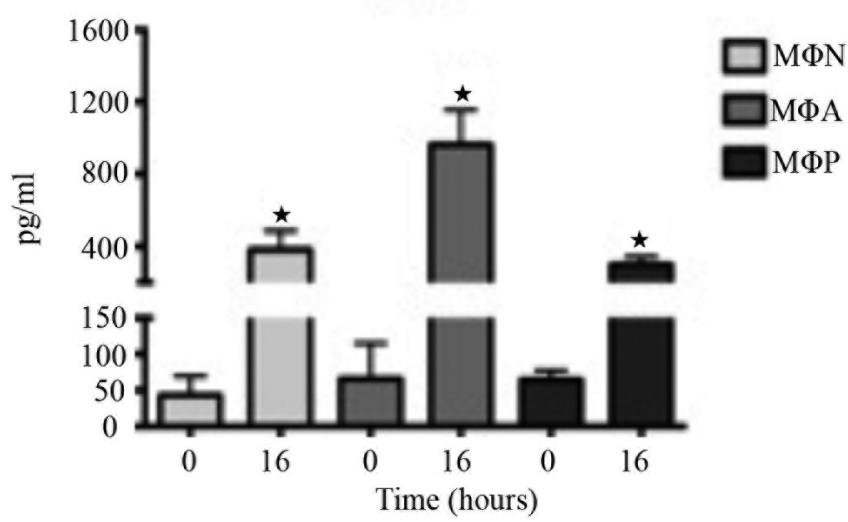

Fig. 4

Quantitation of the pro-inflammatory cytokines/chemokine IL-1 $\beta$, TNF- $\alpha$ and CCL5/RANTES in conditioned media from MФN, MФP and $M \Phi A$, cultured for $16 \mathrm{~h}$ post-infection

(a) mRNA expression levels determined by quantitative RT-PCR. ${ }^{*}$ Indicates statistically significant differences between $\mathrm{M} Ф N$ and $M Ф P$; ${ }^{\circ}$ indicates statistically significant differences between MФA and МФP. (b) Pro-inflammatory cytokine protein levels were determined by immunobead assays; ${ }^{\star}$ indicates statistically significant differences between cultures at $\mathrm{T}_{0}$ and $\mathrm{T}_{16}$ in $\mathrm{M} \Phi \mathrm{N}, \mathrm{M} \Phi \mathrm{A}$ and $\mathrm{M} \Phi \mathrm{P}$. 
(Santoro et al., 2003), thus NF- $\kappa$ B is an attractive target for viral pathogens. Herein, we observed that acute and persistent RSV infection in a macrophage cell line preferentially activated the non-canonical NF- $\kappa \mathrm{B}$ signaling pathway and this response was associated with expression of pro-inflammatory cytokines. Because we observed constitutive processing of p100 into p52 in MФP, our results suggest that RSV persistence might be associated with chronic inflammation, mediated at least in part by signaling of the non-canonical NF- $\kappa B$ pathway.

Airway epithelial cells are not the only targets for RSV, as viral RNA and proteins have been detected in alveolar macrophages of naturally infected humans (Panuska et al., 1993, 1992). In this work, we observed that RSV infected $40-50 \%$ of macrophages at $16 \mathrm{~h}$ pi (data not shown) in our in vitro model; such stimulus induced an early activation of the non-canonical pathway as shown by the observation that p100 was induced as early as $2 \mathrm{~h}$ pi and that the level of the active subunit, p52, was increased in parallel up to $16 \mathrm{~h}$ pi. In contrast, expression of p105, a component of the canonical pathway, significantly declined by $8 \mathrm{~h}$ pi, and the p50 subunit was never detected. Likewise, we observed constitutive expression and processing of p100 in МФP when compared to MФN. However, МФP showed lower levels of p52 than did MФA, suggesting that activation of the non-canonical pathway during RSV persistence might be modulated in some way. There was no evidence of induction of p105 or it's processing into p50 in МФР, suggesting preferential activation of the non-canonical pathway as in acute infection. However, we cannot guarantee that the canonical pathway was not active since very low levels of p50 were observed. We previously described that transcription of the IFN- $\beta$ gene is constitutive in MФP; since transcription of this gene is dependent on NF- $\kappa \mathrm{B}$ canonical elements and of the transcription factor IRF-3 (constitutively localized to the nucleus during RSV persistence), we speculate that the canonical pathway remained active in MФP (Rivera-Toledo et al., 2015). It has been reported that the precursor protein p105 is constitutively processed at a low level in most cell types (Sun, 2012), but its transcriptional activity is induced under specific stimuli. In contrast, p100 processing is induced by a specific signal, producing the active nuclear-localized p52 subunit (Sun, 2012), thus suggesting that the p52 observed in MФA and МФP was playing its role as a transcription factor. Evaluation of transcription of the genes IL-1 $\beta$, TNF- $\alpha$, and CCL5/RANTES, which contain promoter regions that depend on NF- $\mathrm{BB}$ dimers (Pahl, 1999) showed active expression of these three genes but at higher levels in МФР than in МФA. However, quantitative analysis of cytokines displayed increased concentrations in $\mathrm{M} Ф A$ compared to $\mathrm{M} Ф \mathrm{P}$, a result that did not correlate with the mRNA levels, thus suggesting post-transcriptional regulation of cytokine protein levels during RSV persistence.

Overall, these results indicate that acute RSV infection is a triggering signal for selective p100 processing in macrophages, while sustained RSV infection in MФP was associated with constitutive presence of p52; both types of viral infection were related to increased transcription of proinflammatory cytokines. However, their protein levels did not correlate with mRNA during RSV persistence, suggesting a post-transcriptional regulation mechanism that may help to avoid an exacerbated inflammatory response that could compromise the chronic viral infection.

Acknowledgments. The authors thank Josefina Bolado, Head of the Scientific Paper Translation Department, from Division of Investigation at Faculty of Medicine, UNAM, for revising the Englishlanguage version of this manuscript. This research was supported by grants from the Consejo Nacional de Ciencia y Tecnología, México (Grant 179838), by the Dirección General de Asuntos del Personal Académico, Universidad Nacional Autónoma de México (Grant PAPIIT IN218916), and by the Faculty of Medicine, UNAM.

\section{References}

Branche AR, Falsey AR (2015): Respiratory syncytial virus infection in older adults: an under-recognized problem. Drugs and Aging 32, 261-269. https://doi.org/10.1007/ s40266-015-0258-9

Choudhary S, Boldogh S, Garofalo R, Jamaluddin M, Brasier AR (2005): Respiratory syncytial virus influences NF-kappaB-dependent gene expression through a novel pathway involving MAP3K14/NIK expression and nuclear complex formation with NF-kappaB2. J. Virol. 79, 8948-8959. https://doi.org/10.1128/JVI.79.14.8948-8959.2005

Dave KA, Norris EL, Bukreyev AA, Headlam MJ, Buchholz UJ, Singh T, Collins PL, Gorman JJ. (2014): A comprehensive proteomic view of responses of A549 type II alveolar epithelial cells to human respiratory syncytial virus infection. Mol. Cell. Proteomics 13, 3250-3269. https://doi. org/10.1074/mcp.M114.041129

Gaona J, Santiago-Olivares C, Ortega E, Gómez B (2014): Respiratory syncytial virus persistence in macrophages upregulates fcgamma receptors expression. Viruses 6, 624-639. https://doi.org/10.3390/v6020624

Garofalo R et al. (1996): Transcriptional activation of the interleukin- 8 gene by respiratory syncytial virus infection in alveolar epithelial cells: nuclear translocation of the RelA transcription factor as a mechanism producing airway mucosal inflammation. J. Virol. 70, 8773-8781. 0022538X (Print) $\backslash \mathrm{r} 0022-538 \mathrm{X}$ (Linking)

Génin P, Algarté M, Roof P, Lin R, Hiscott J (2000): Regulation of RANTES chemokine gene expression requires cooperativity between NF-kappa B and IFN-regulatory factor transcription factors. J. Immunol. 164, 5352-5361. https:// doi.org/10.4049/jimmunol.164.10.5352

Gilmore T (2006): Introduction to NF-jB: players, pathways, perspectives. Oncogene 25, 6680-6684. doi: 10.1038/ sj.onc.1209954 https://doi.org/10.1038/sj.onc.1209954

Grandvaux N, Guan X, Yoboua F, Zucchini N, Fin K, Doyon P, Martin L, Servant MJ, Charties S (2014): Sustained acti- 
vation of interferon regulatory factor 3 during infection by paramyxoviruses requires MDA5. J. Innate Immun. 6, 650-662. https://doi.org/10.1159/000360764

Hall CB, Simőes EAF, Anderson LJ (2013): Clinical and epidemiologic features of respiratory syncytial virus. Curr. To.p Microbiol. Immunol. 372, 39-57. https://doi. org/10.1007/978-3-642-38919-1 2

Hayden MS, Ghosh S (2008): Shared principles in NF-kappaB signaling. Cell 132, 344-362. https://doi.org/10.1016/j. cell.2008.01.020

Jamaluddin M, Casola A, Garofalo RP, Han Y, Elliott T, Ogra PL, Brasier AR (1998): The major component of IkappaBalpha proteolysis occurs independently of the proteasome pathway in respiratory syncytial virus-infected pulmonary epithelial cells. J. Virol. 72, 4849-4857.

Karin M, Lin A (2002): NF- $\mathrm{BB}$ at the crossroads of life and death. Nat. Immunol. 3, 221-227. https://doi.org/10.1038/ ni0302-221

Kokturk N, Bozdayi G2, Yilmaz S, Doğan B, Gulbahar O, Rota S, Tatlicioglu T (2015): Detection of adenovirus and respiratory syncytial virus in patients with chronic obstructive pulmonary disease: Exacerbation versus stable condition. Mol. Med. Rep. 12, 3039-3046. https://doi.org/10.3892/ mmr.2015.3681

Liu P, Jamaluddin M, Li K, Garofalo RP, Casola A, Brasier AR (2007): Retinoic acid-inducible gene I mediates early antiviral response and Toll-like receptor 3 expression in respiratory syncytial virus-infected airway epithelial cells. J. Virol. 81, 1401-1411. https://doi.org/10.1128/ JVI.01740-06

Mejías A, Chávez-Bueno S, Gómez AM, Somers C, Estripeaut D, Torres JP, Jafri HS, Ramilo O (2008): Respiratory syncytial virus persistence: evidence in the mouse model. Pediatr. Infect. Dis. J. 27, S60-S62. https://doi.org/10.1097/ INF.0b013e3181684d52

Openshaw PJ, Dean GS, Culley FJ (2003): Links between respiratory syncytial virus bronchiolitis and childhood asthma: clinical and research approaches. Pediatr. Infect. Dis. J. 22, S58-S64. https://doi.org/10.1097/01. inf.0000053887.26571.eb

Pahl HL (1999): Activators and target genes of Rel/NF-kappaB transcription factors. Oncogene 18, 6853-6866. https:// doi.org/10.1038/sj.onc. 1203239
Panuska JR, Hertz MI, Taraf H, Villani A, Cirino NM (1992): Respiratory syncytial virus Infection of alveolar macrophages in adult transplant patients. Am. Rev. Respir. Dis. 145, 934939. https://doi.org/10.1164/ajrccm/145.4_Pt 1.934

Piedimonte G (2013): Respiratory syncytial virus and asthma: speed-dating or long-term relationship? Curr. Opin. Pediatr. 25, 344-349. https://doi.org/10.1097/ MOP.0b013e328360bd2e

Ravi LI, Li L, Sutejo R, Chen H, Wong PS, Tan BH, Sugrue RJ (2013): A systems-based approach to analyse the host response in murine lung macrophages challenged with respiratory syncytial virus. BMC Genomics 14, 190. https://doi.org/10.1186/1471-2164-14-190

Rivera-Toledo E, Torres-González L, Gómez B (2015): Respiratory syncytial virus persistence in murine macrophages impairs IFN- $\beta$ response but not synthesis. Viruses 7 , 5361-5374. https://doi.org/10.3390/v7102879

Santoro MG (2003) NEW EMBO MEMBER'S REVIEW: NFkappaB and virus infection: who controls whom. EMBO J. 22, 2552-2560. https://doi.org/10.1093/emboj/cdg267

Sarmiento RE, Tirado R, Gómez B (2002): Characteristics of a respiratory syncytial virus persistently infected macrophagelike culture. Virus Res. 84, 45-58. https://doi.org/10.1016/ S0168-1702(01)00420-8

Shih VF-S, Tsui R, Caldwell A, Hoffmann A (2011): A single NFKB system for both canonical and non-canonical signaling. Cell Res. 21, 86-102. https://doi.org/10.1038/ cr.2010.161

Siebenlist U, Franzoso G, Brown K (1994): Structure, regulation and function of NF-kB. Annu. Rev. Cell. Biol. 10, 405-455. https://doi.org/10.1146/annurev.cb.10.110194.002201

Sikkel MB, Quint JK, Mallia P, Wedzicha J a, Johnston SL (2008): Respiratory syncytial virus persistence in chronic obstructive pulmonary disease. Pediatr. Infect. Dis. J. 27, S63-S70. https://doi.org/10.1097/INF.0b013e3181684d67

Sun S (2012): The noncanonical NF- $\kappa B$ pathway. Immunol. Rev. 246, 125-140. https://doi.org/10.1111/j.1600-065X.2011.01088.X

Szabo SM, Levy AR, Gooch KL, Bradt P, Wijaya H, Mitchell I (2013): Paediatric respiratory reviews elevated risk of asthma after hospitalization for respiratory syncytial virus infection in infancy. Paediat. Respir. Rev. 13, S9-S15. https://doi. org/10.1016/S1526-0542(12)70161-6 